\title{
DESPOLPAMENTO, ARMAZENAMENTO E TEMPERATURA NA GERMINAÇÃO DE SEMENTES DE PALMEIRA REAL AUSTRALIANA ${ }^{1}$
}

\author{
Márcia Torres Teixeira ${ }^{2}$, Henrique Duarte Vieira ${ }^{2}$, Fábio Luiz Partelli ${ }^{3}$, Roberto Ferreira da Silva ${ }^{2}$
}

\section{ABSTRACT \\ PULPING, STORAGE, AND TEMPERATURE ON THE GERMINATION OF AUSTRALIAN KING PALM SEEDS}

The Australian King palm (Archontophoenix alexandrae) is suitable for the rational exploitation of heart of palm, mainly due to its early maturity, rusticity, and heart of palm quality. Aiming at studying the effect of pulping, storage, and temperature on the germination of its seeds, two experiments were carried out. The first one combined five pulping methods (hand pulping with the aid of a sieve, after harvesting; pulping in sulfuric acid; moisturized fruits stored in plastic bags for three days, for fermentation; fruits immersed in water for three days, with the water being daily replaced; and not pulped fruits) and four storage periods $(0,30,75$, and 120 days $)$, at $20^{\circ} \mathrm{C}$. The design was completely randomized, in a $5 \times 4$ factorial scheme, with five replications of 30 seeds. For the second experiment, seeds extracted after fruits were immersed in water for three days were taken to germinate in a completely randomized design, with six treatments and five replications of 30 seeds, under different temperatures (constant temperatures of $25^{\circ} \mathrm{C}, 30^{\circ} \mathrm{C}, 35^{\circ} \mathrm{C}$, and $40^{\circ} \mathrm{C}$, as well as alternating temperatures of $30^{\circ} \mathrm{C} / 20^{\circ} \mathrm{C}$ (day/ night) and $35^{\circ} \mathrm{C} / 25^{\circ} \mathrm{C}$ (day/night)). The germination percentage and the germination speed index were evaluated and the pulping method with fruits immersed in water was considered the best one for preserving seeds before and after storage, as well as $25^{\circ} \mathrm{C}$ the best temperature for promoting the germination of the Australian King palm seeds.

KEY-WORDS: Archontophoenix alexandrae (F. v. Muell.) H. A. Wendl. \& Drude; seeds vigor; heart of palm.

\section{INTRODUÇÃO}

A produção anual brasileira de palmito, em 2009, foi de, aproximadamente, 5 mil toneladas, movimentando mais de 7 milhões de reais (IBGE 2009). No País, apenas 3\% da produção de palmito é proveniente de áreas com manejo autosustentado,

\section{RESUMO}

A Palmeira Real Australiana (Archontophoenix alexandrae) é adequada à exploração racional de palmito, devido, principalmente, às suas características de precocidade, rusticidade e qualidade do palmito. O objetivo deste trabalho foi avaliar o efeito do despolpamento, armazenamento e temperatura sobre a germinação de sementes de Palmeira Real Australiana. Foram realizados dois experimentos. O primeiro constituiu-se da combinação de cinco métodos de despolpamento (despolpamento manual em peneira, após a colheita; despolpamento em ácido sulfúrico; frutos umedecidos e colocados em sacos plásticos, por três dias, para fermentar; frutos imersos em água, por três dias, sendo a água trocada diariamente; e frutos não despolpados) e quatro períodos de armazenamento (0, 30, 75 e 120 dias), a $20^{\circ} \mathrm{C}$. Adotou-se o delineamento inteiramente casualizado, em esquema fatorial $5 \times 4$, com cinco repetições de 30 sementes. No segundo experimento, as sementes extraídas após os frutos ficarem imersos em água por três dias foram colocadas para germinar, em delineamento inteiramente casualizado, com seis tratamentos e cinco repetições de 30 sementes, sob diferentes condições de temperatura (temperaturas constantes de $25^{\circ} \mathrm{C}, 30^{\circ} \mathrm{C}, 35^{\circ} \mathrm{C}$ e $40^{\circ} \mathrm{C}$ e alternadas de $30^{\circ} \mathrm{C} / 20^{\circ} \mathrm{C}$ (dia/noite) e $35^{\circ} \mathrm{C} / 25^{\circ} \mathrm{C}$ (dia/noite)). Avaliou-se a percentagem de germinação e o Índice de Velocidade de Germinação (IVG) e verificou-se que o despolpamento por imersão em água foi o melhor tratamento para preservar a viabilidade inicial e após o armazenamento das sementes, e que a temperatura de $25^{\circ} \mathrm{C}$ foi considerada ideal para promover a germinação de sementes de Palmeira Real Australiana.

PALAVRAS-CHAVE: Archontophoenix alexandrae (F. v. Muell.) H. A. Wendl. \& Drude; vigor de sementes; palmito.

caracterizando-se como uma atividade altamente extrativista, o que dificulta a padronização da matéria-prima (Migliano 2002). Assim, com o cultivo racional de espécies apropriadas à extração do palmito, a produção e as exportações nacionais tendem a aumentar. Além disto, pode auxiliar na redução da extração de palmitos de palmeiras nativas, contri-

1. Trabalho recebido em abr./2010 e aceito para publicação em set./2011 (nº registro: PAT 9617/ DOI: 10.5216/pat.v41i3.9617).

2. Universidade Estadual do Norte Fluminense Darcy Ribeiro, Campos dos Goytacazes, RJ, Brasil.

E-mails: mt-teixeira@uol.com.br, henrique@uenf.br, roberto@uenf.br.

3. Universidade Federal do Espírito Santo, Departamento de Ciências Agrárias e Biológicas, São Mateus, ES, Brasil.

E-mail: partelli@yahoo.com.br. 
buindo, consequentemente, para a preservação dos recursos naturais (Bovi 1998).

Uma alternativa é o uso das espécies de Palmeira Real Australiana (Archontophoenix alexandrae e $A$. cunninghamiana), que têm sido consideradas adequadas para a exploração racional de palmito, devido, principalmente, às suas características de precocidade, rusticidade e qualidade do palmito, gerando empregos e rentabilidade à toda a cadeia produtiva (Bovi 1998, Lorenzi et al. 2004).

A propagação comercial da Palmeira Real Australiana é seminífera e as sementes apresentam alto teor de fibras e ácido palmítico, oléico e linoléico (Vallilo et al. 2004), sendo consideradas albuminosas, com endosperma ruminado, embrião lateral, periférico e relativamente indiferenciado, sendo a germinação criptocotiledonar hipógea (Charlo et al. 2006). São consideradas recalcitrantes, perdendo o vigor e diminuindo a germinação quando secas a umidade inferior a 31,5\% (Martins et al. 2003). Todavia, Stringheta et al. (2004) relatam que as sementes perdem o vigor e o potencial germinativo quando a umidade atinge menos de $24,5 \%$. De maneira semelhante, as sementes de outras palmeiras, como o palmito vermelho (Martins et al. 2007) e o açaí, também são prejudicadas pela secagem (Nascimento et al. 2007).

Trabalhos de Ferreira \& Gentil (2006) sugeriram que a retirada do endocarpo melhora a germinação de sementes de Palmeira Tucumã. Luz et al. (2011) observaram que apenas a embebição da semente não proporcionou efeitos significativos na velocidade de germinação e germinação total de sementes de Palmeira Real Australiana.

Diversos fatores influenciam no processo de velocidade e uniformidade de germinação (Carvalho \& Nakagawa 2000). Assim, o objetivo deste trabalho foi avaliar o efeito do despolpamento, período de armazenamento e temperatura sobre o processo germinativo de sementes de Palmeira Real Australiana.

\section{MATERIAL E MÉTODOS}

As sementes de Archontophoenix alexandrae (F. v. Muell.) H. A. Wendl. \& Drude utilizadas neste trabalho foram colhidas em plantas cultivadas no Campus da Universidade Federal de Viçosa (MG). O clima é tropical de altitude, com precipitação média anual de 1.000-1.500 mm e média anual da temperatura máxima e mínima de $27,5^{\circ} \mathrm{C}$ e $14^{\circ} \mathrm{C}$, respectivamente.
As sementes utilizadas nos ensaios originaram-se de frutos totalmente maduros, com coloração vermelho intenso. Após a colheita, os mesmos foram transportados para a Universidade Estadual do Norte Fluminense Darcy Ribeiro, em Campos dos Goytacazes $(\mathrm{RJ})$, onde os experimentos de laboratório foram desenvolvidos, entre 2005 e 2006.

No ensaio 1, estudou-se o efeito de cinco métodos de despolpamento de frutos (extração de sementes) e quatro períodos de armazenamento das sementes. Adotou-se o delineamento inteiramente casualizado, com distribuição fatorial $5 \times 4$, com cinco repetições de 30 sementes.

Os métodos de despolpamento de frutos estudados consistiram de: 1) despolpamento manual em peneira (logo após a colheita); 2) despolpamento em ácido sulfúrico (96\% PA), por cinco minutos; 3 ) frutos umedecidos e colocados em sacos plásticos, por três dias, para fermentar; 4) frutos imersos em água, por três dias, sendo a água trocada diariamente; 5) tratamento testemunha (frutos não despolpados). Os frutos submetidos aos tratamentos 3 e 4 tiveram o processo de despolpamento concluído com o uso do despolpamento manual em peneira.

Após a montagem dos tratamentos de despolpamento, as sementes foram dispostas sobre caixas de papelão, por três dias, à temperatura de, aproximadamente, $25^{\circ} \mathrm{C}$, para uniformização da umidade. Todas as sementes foram submetidas ao tratamento de desinfestação com solução de hipoclorito de sódio $(0,5 \%)$, por 15 minutos, após o armazenamento.

As sementes foram armazenadas por 0, 30, 75 e 120 dias, em câmara de germinação tipo BOD, acondicionadas em sacos plásticos de alta densidade, a $20^{\circ} \mathrm{C}$, sendo esta a temperatura máxima recomendada por Martins et al. (2004), para o armazenamento de sementes de Palmeira Jussara (Euterpe edulis).

O desempenho das sementes foi avaliado pelo teste de germinação e Índice de Velocidade de Germinação (IVG). Para isto, as sementes foram dispostas em rolos de papel germiteste, contendo duas folhas por baixo e uma por cima, previamente umedecidas na proporção de 2,5 vezes a sua massa. Os rolos foram agrupados e colocados dentro de sacos plásticos, dispostos um sobre o outro, de forma invertida. Permaneceram por 45 dias em câmara de germinação, à temperatura alternada de $30^{\circ} \mathrm{C} / 20^{\circ} \mathrm{C}$ (dia/noite), durante 8/16 horas (luz/escuro) (Martins et al. 2007).

Foram avaliados a percentagem de germinação (protrusão da radícula, com, pelo menos, $5 \mathrm{~mm}$ de 
comprimento) e o Índice de Velocidade de Germinação (IVG) (Maguire 1962, Brasil 1992).

Os dados foram submetidos a análise de variância. Os níveis do fator qualitativo (despolpamento) foram comparados pelo teste Tukey ( $5 \%$ ), enquanto, para o fator quantitativo (período de armazenamento), procedeu-se ao ajuste de modelos de regressão. Foi utilizado, para as análises estatísticas, o programa SAEG (2007).

No ensaio 2, estudou-se a resposta germinativa de sementes de Palmeira Real Australiana, em função de diferentes condições de temperaturas. Adotou-se o delineamento inteiramente casualizado, com seis tratamentos e cinco repetições de 30 sementes.

Foram estudadas as temperaturas constantes de $25^{\circ} \mathrm{C}, 30^{\circ} \mathrm{C}, 35^{\circ} \mathrm{C}$ e $40^{\circ} \mathrm{C}$ e as alternadas de $30^{\circ} \mathrm{C} / 20^{\circ} \mathrm{C}$ (dia/noite) e $35^{\circ} \mathrm{C} / 25^{\circ} \mathrm{C}$ (dia/noite). As sementes utilizadas foram extraídas de frutos despolpados, após permanecerem por três dias imersos em água, como descrito no ensaio 1. As sementes foram dispostas em rolos de papel germiteste e estes acondicionados em sacos plásticos, posicionados um sobre o outro, de forma invertida, e levados para câmaras de germinação tipo BOD. As sementes permaneceram por até 45 dias em regime de $8 / 16$ horas (luz/escuro).

Foram avaliados a percentagem de germinação (protrusão da radícula, com, pelo menos, $5 \mathrm{~mm}$ de comprimento) e o Índice de Velocidade de Germinação (IVG) (Maguire 1962, Brasil 1992).

Os dados foram submetidos a análise de variância e as médias comparadas pelo teste Tukey (5\%). Foi utilizado, para as análises estatísticas, o programa SAEG (2007).

\section{RESULTADOS E DISCUSSÃO}

\section{Despolpamento de frutos e armazenamento de se- mentes}

As sementes oriundas de frutos despolpados em ácido sulfúrico concentrado (96\% PA), por cinco minutos, não germinaram, indicando que o tratamento com ácido sulfúrico foi letal às sementes de Palmeira Real Australiana. Ledo et al. (2002) também observaram efeito prejudicial, ao tratarem sementes de pupunha em ácido sulfúrico concentrado, por quatro minutos. Contudo, procedimento similar foi eficiente para superação de dormência em sementes de Adenanthera pavonina L. (Costa et al. 2010).

A percentagem final de germinação, para as sementes oriundas de frutos que não foram despolpados, alcançou valor máximo $(92,1 \%)$ aos 41 dias de armazenamento e vigor máximo $(4,94)$ aos 39 dias, sendo que, antes deste ponto, a germinação foi menor, provavelmente por dormência imposta pela casca do fruto. Após o ponto de máxima germinação, foi observada perda de vigor e germinação, causada pela deterioração das sementes (Figura 1). Estes resultados evidenciam que o desempenho das sementes de frutos não despolpados de Palmeira Real Australiana melhora com, aproximadamente, 40 dias de armazenamento, resultado muito próximo ao verificado por Martins et al. (2000a), os quais afirmam que a manutenção da polpa foi prejudicial à qualidade das sementes de palmito vermelho.

Nas sementes de frutos despolpados manualmente em peneira, logo após a colheita, verificou-se

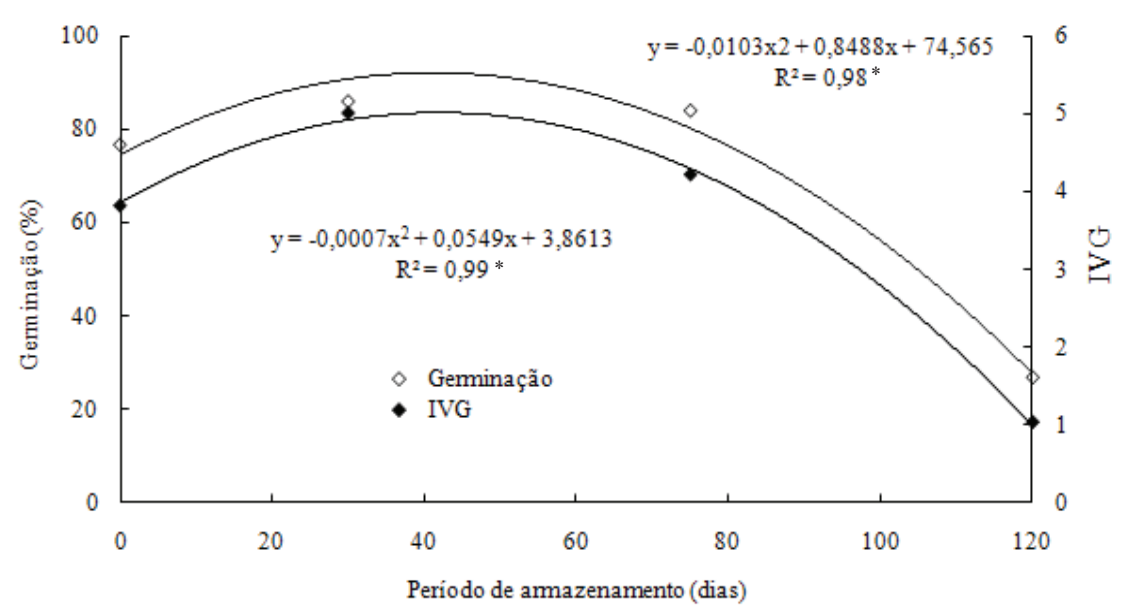

Figura 1. Percentagem de germinação e Índice de Velocidade de Germinação (IVG) de sementes de Palmeira Real Australiana sem despolpamento, armazenadas por diferentes períodos (Campos dos Goytacazes, RJ, 2005/2006). * Regressões significativas ( $\mathrm{p}<0$,05). 
maior percentagem de germinação e IVG, quando as sementes foram semeadas logo após a extração (Figura 2). Neste processo de despolpamento, o armazenamento não resultou em vantagem para a germinação das sementes, ocorrendo, exatamente, o contrário: à medida que o tempo de armazenamento aumentou, a germinação e o IVG reduziram-se acentuadamente. Os resultados indicaram que as sementes de Palmeira Real extraídas manualmente em peneiras, após a colheita, não devem ser armazenadas, corroborando o trabalho de Marcus \& Banks (1999).

No método de despolpamento onde os frutos passaram por processo de fermentação em sacos plásticos fechados, durante três dias, com posterior extração das sementes em peneira (Figura 3), a germinação alcançou valor máximo $(97,1 \%)$ com 15 dias de armazenamento, obtido pela derivada primeira da equação de regressão. A partir deste período de armazenamento, observou-se redução significativa da germinação, até o final do armazenamento, evidenciando o comportamento recalcitrante destas sementes (Martins et al. 2003). Assim como a germinação, as sementes apresentaram os maiores valores de IVG $(5,83)$ com 15 dias de armazenamento, reduzindo-se, posteriormente, a sua velocidade de germinação, alcançando o menor

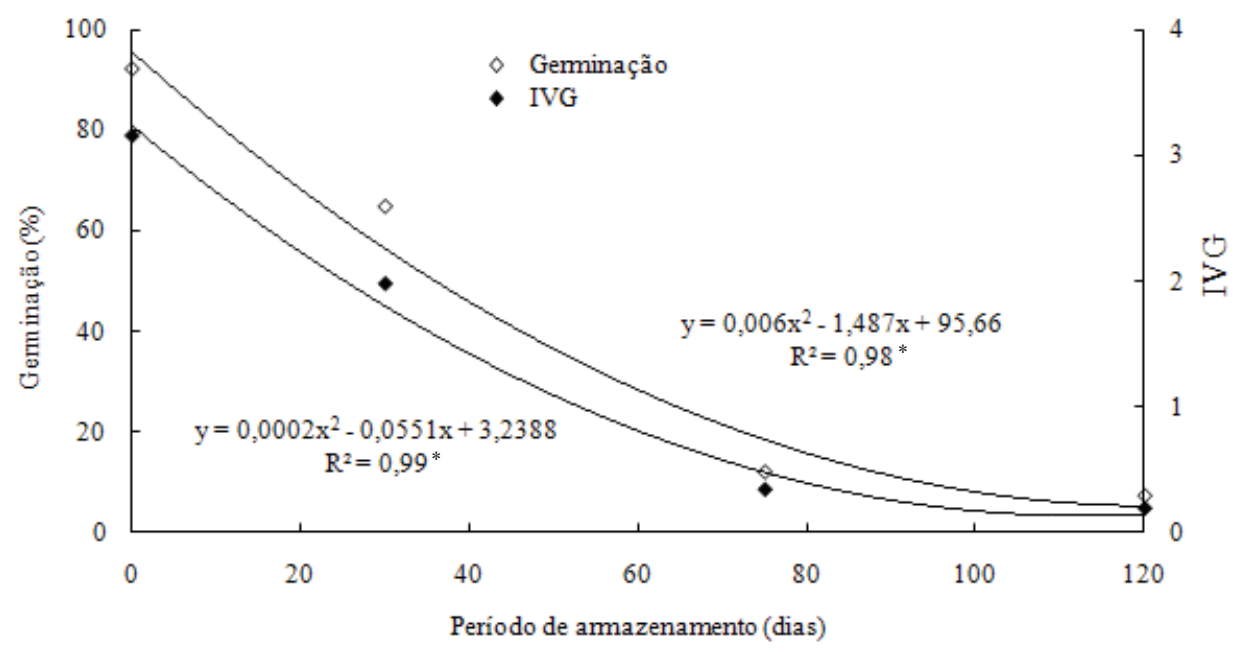

Figura 2. Percentagem de germinação e Índice de Velocidade de Germinação (IVG) de sementes de Palmeira Real Australiana despolpadas manualmente em peneira, armazenadas por diferentes períodos (Campos dos Goytacazes, RJ, 2005/2006). * Regressões significativas $(\mathrm{p}<0,05)$.

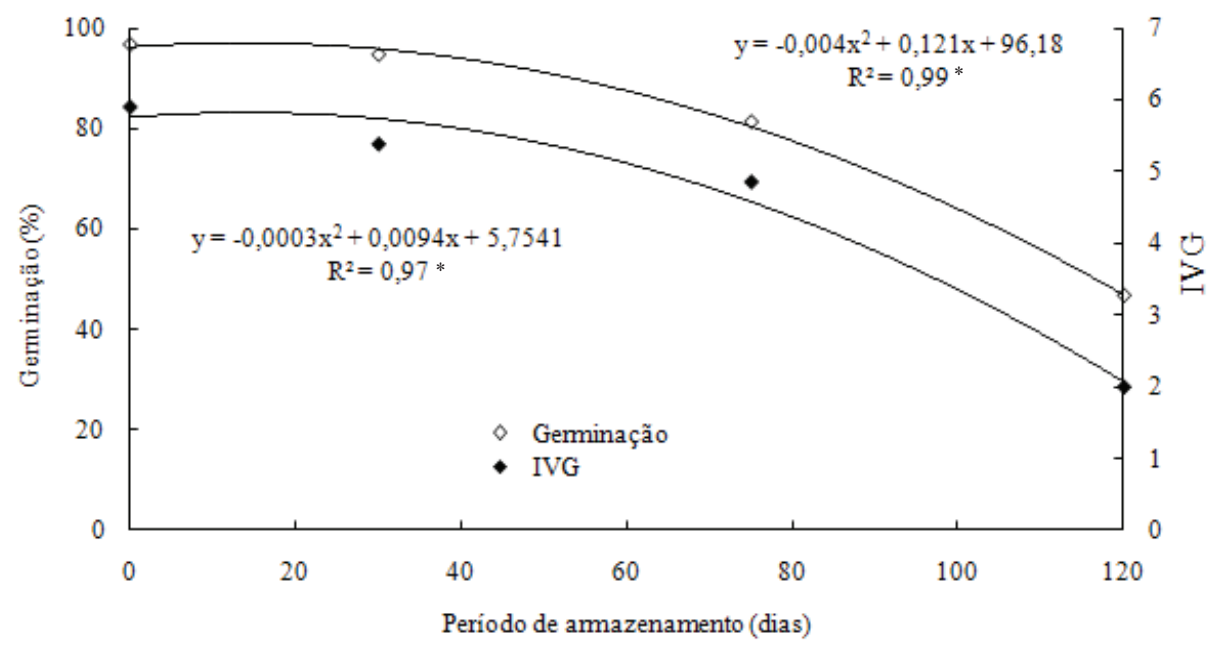

Figura 3. Percentagem de germinação e Índice de Velocidade de Germinação (IVG) de sementes de Palmeira Real Australiana fermentadas e armazenadas por diferentes períodos (Campos dos Goytacazes, RJ, 2005/2006). * Regressões significativas $(p<0,05)$. 
valor $(2,56) 120$ dias após o início do armazenamento (Figura 3).

As sementes de frutos embebidos por três dias (Figura 4) apresentaram resposta germinativa, no início do armazenamento, muito próxima à das sementes que fermentaram por três dias (Figura 3). Após 120 dias do início do experimento, as sementes que tiveram a água trocada apresentaram maior percentagem de germinação $(77,6 \%)$ do que as sementes que fermentaram por três dias antes de serem extraídas $(53,1 \%)$, indicando que, para um período maior de armazenamento, as sementes não devem ser fermentadas antes do despolpamento.

Para o IVG, verificou-se comportamento semelhante, no início do armazenamento, entre as sementes de frutos embebidos e fermentados, no entanto, 120 dias após o início do armazenamento, as sementes de frutos embebidos apresentaram IVG $45 \%$ superior ao IVG das sementes fermentadas, $1.350 \%$ superior ao IVG das sementes extraídas imediatamente após a colheita e 179\% superior ao IVG das sementes de frutos não despolpados, indicando que, se necessário o armazenamento das sementes de Palmeira Real Australiana, por até 120 dias, este seria o método de despolpamento recomendado.

Sementes de frutos embebidos em água por três dias foi o tratamento que possibilitou a preservação do maior poder germinativo e maior IVG, durante o armazenamento (Figura 4). A fermentação das sementes por três dias também manteve o poder germinativo e o vigor das sementes, no início do armazenamento (Figura 3). Estes resultados corroboram os relatados por Martins et al. (2004), ao trabalharem com Palmeira Juçara, e confirmam os efeitos benéficos da remoção do mesocarpo da Palmeira Real Australiana observados por Bovi (1998).

Já o despolpamento manual, logo após a colheita, sem tratamento adicional, acelerou a perda do poder germinativo e vigor das sementes, durante o armazenamento. Assim, os resultados indicam que o despolpamento manual sobre peneira, logo após a colheita, sem qualquer pré-tratamento adicional, como imersão ou fermentação, deve ser recomendado somente para sementes que serão utilizadas imediatamente após a colheita.

As sementes de frutos não despolpados alcançaram a menor germinação entre as sementes recém-colhidas $(74,6 \%)$, entretanto, tiveram seu poder germinativo aumentado até 41 dias de armazenamento $(92,0 \%)$.

\section{Temperaturas de germinação}

Analisando-se o efeito de diferentes temperaturas sobre o comportamento germinativo de sementes de Palmeira Real Autraliana, observou-se que, sob temperatura de $25^{\circ} \mathrm{C}$, a germinação das sementes iniciou-se no $15^{\circ}$ dia após a instalação do teste. Utilizando-se a temperatura alternada de $25^{\circ} \mathrm{C} / 35^{\circ} \mathrm{C}$, a germinação iniciou-se no $18^{\circ}$ dia; alternada de $20^{\circ} \mathrm{C} / 30^{\circ} \mathrm{C}$, no $21^{\circ}$ dia; e constante de $30^{\circ} \mathrm{C}$, no $24^{\circ}$ dia. Os menores percentuais de germi-

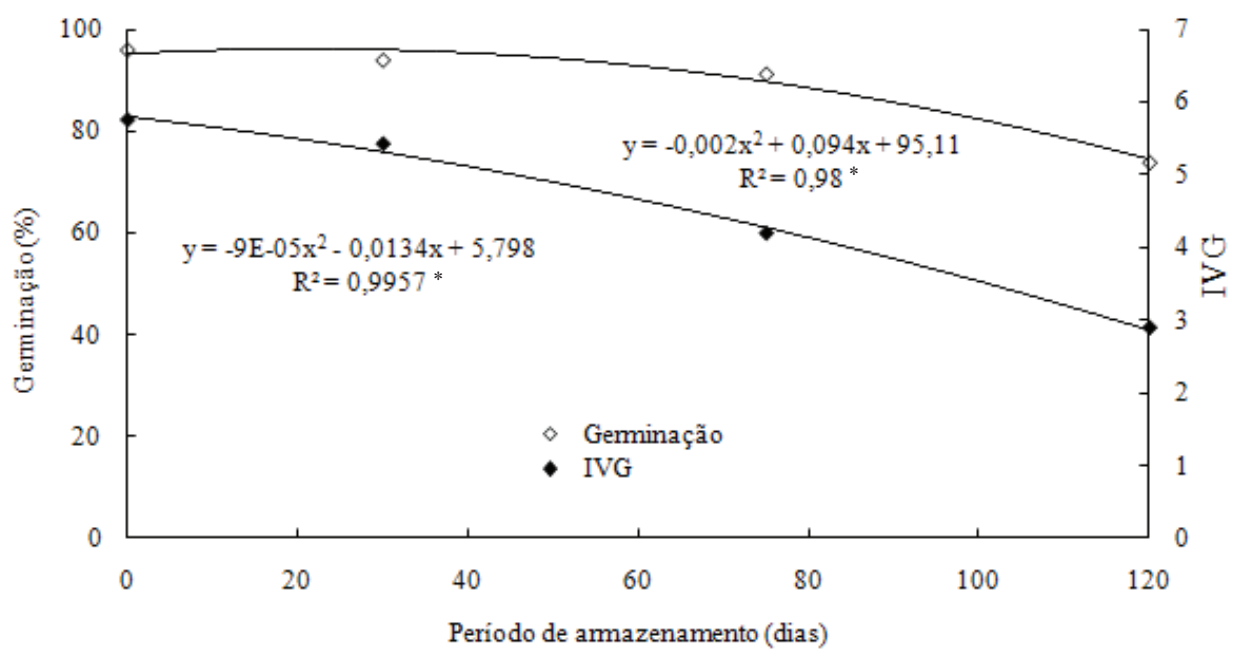

Figura 4. Percentagem de germinação e Índice de Velocidade de Germinação (IVG) de sementes de Palmeira Real Australiana imersas em água, por três dias, armazenadas por diferentes períodos (Campos dos Goytacazes, RJ, 2005/2006). * Regressões significativas $(\mathrm{p}<0,05)$. 
nação foram observados em sementes submetidas às temperaturas constantes de $35^{\circ} \mathrm{C}$ e $40^{\circ} \mathrm{C}$, que apresentaram $6 \%$ e $0 \%$ de germinação, respectivamente (Figura 5).

A percentagem final de germinação foi semelhante entre os tratamentos sob temperatura constante de $25^{\circ} \mathrm{C}$ e $30^{\circ} \mathrm{C}$ e temperaturas alternadas de $20^{\circ} \mathrm{C} / 30^{\circ} \mathrm{C}$ e $25^{\circ} \mathrm{C} / 35^{\circ} \mathrm{C}$, alcançando valores superiores aos observados por Bovi \& Cardoso (1978) e Andrade et al. (1996), ao submeterem sementes de Euterpe edulis Mart. à temperatura alternada de $20^{\circ} \mathrm{C} / 30^{\circ} \mathrm{C}$. No entanto, os resultados foram inferiores às percentagens de germinação obtidas por Martins et al. (2000b), à temperatura alternada de $20^{\circ} \mathrm{C} / 30^{\circ} \mathrm{C}$, com sementes de E. espiritosantensis, indicando que a espécie é determinante na temperatura ótima de germinação de sementes, entre as palmeiras citadas, apesar de algumas diferenças existirem nas metodologias utilizadas pelos referidos autores.

As sementes apresentaram maior IVG quando foram colocadas para germinar à temperatura de $25^{\circ} \mathrm{C}$ (Figura 6), diferindo dos resultados obtidos por Meerow (1991), que encontrou a faixa de $29-35^{\circ} \mathrm{C}$ como sendo a faixa de temperatura adequada para a germinação de sementes de palmeira. O IVG não diferiu entre os tratamentos com temperatura alternada de $30^{\circ} \mathrm{C} / 20^{\circ} \mathrm{C}$ e $35^{\circ} \mathrm{C} / 25^{\circ} \mathrm{C}$, bem como entre as temperaturas alternadas de $30^{\circ} \mathrm{C} / 20^{\circ} \mathrm{C}$ e constante de $30^{\circ} \mathrm{C}$. Estes resultados corroboram os obtidos por Borges \& Rena (1993), os quais relataram que a temperatura adequada para a germinação da maioria das sementes está na faixa de $20-30^{\circ} \mathrm{C}$.
A menor velocidade de germinação das sementes de Palmeira Real foi observada à temperatura de $35^{\circ} \mathrm{C}$, concordando com Marcos Filho (1986), que menciona as temperaturas de $35-40^{\circ} \mathrm{C}$ como sendo as temperaturas máximas para germinação de sementes de espécies tropicais e subtropicais.

\section{CONCLUSÕES}

1. O despolpamento dos frutos imersos em água por três dias propiciou o máximo índice de germinação das sementes recém-colhidas, sem resultar em grandes perdas na viabilidade das mesmas, ao final do armazenamento.

2. A temperatura constante de $25^{\circ} \mathrm{C}$ mostrou-se ideal para a germinação de sementes de Palmeira Real Australiana.

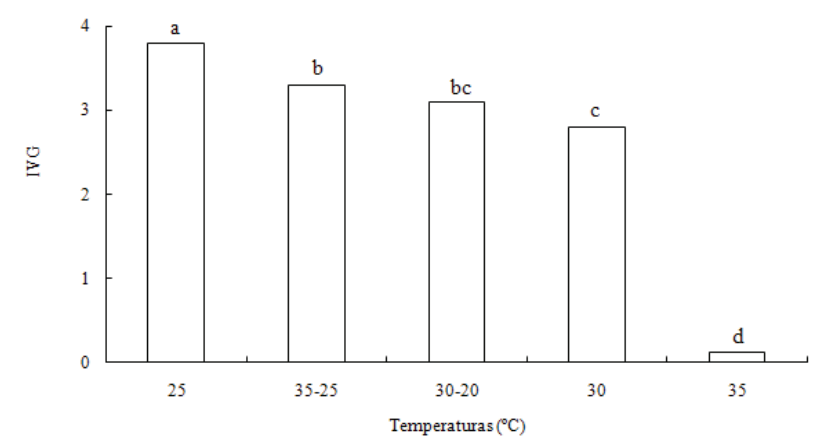

Figura 6. Índice de Velocidade de Germinação (IVG) de sementes de Palmeira Real Australiana submetidas a diferentes temperaturas (Campos dos Goytacazes, RJ, 2005/2006).

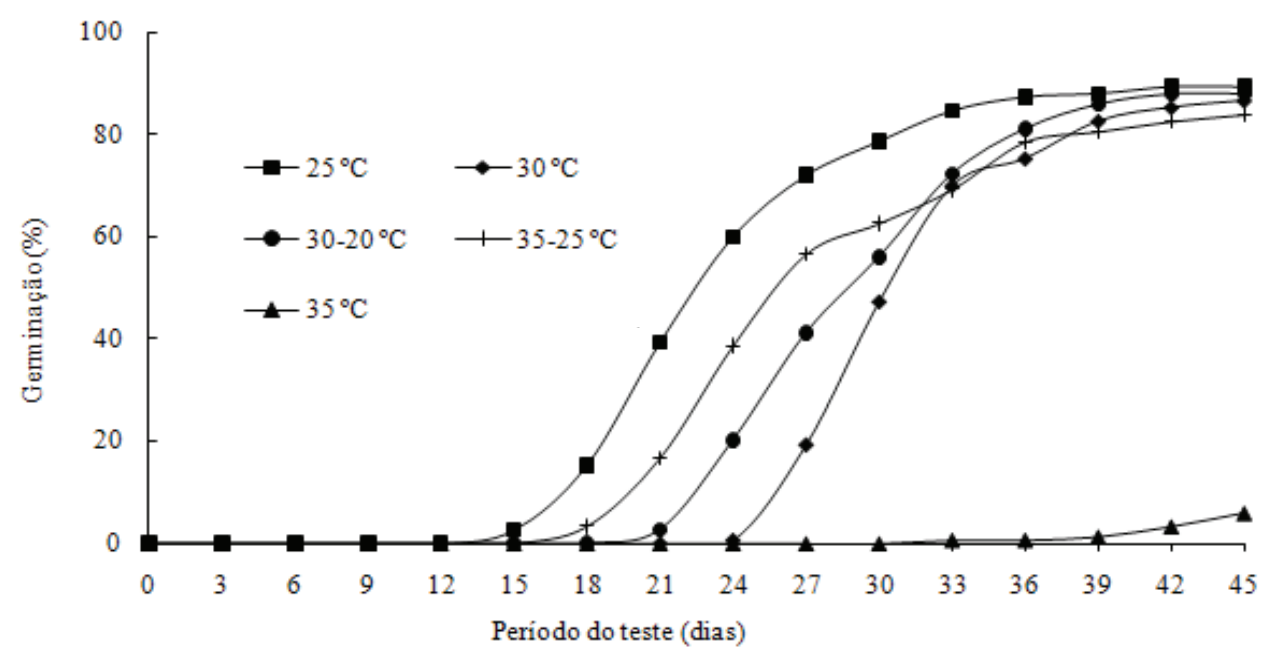

Figura 5. Percentagem de germinação de sementes de Palmeira Real Australiana submetidas a diferentes temperaturas (Campos dos Goytacazes, RJ, 2005/2006). 


\section{REFERÊNCIAS}

ANDRADE, A. C. S.; MALAVASI, M. M.; COSTA, F. A. Conservação de palmiteiro (Euterpe edulis Mart.): efeito da temperatura de armazenamento e do grau de umidade das sementes. Revista Brasileira de Sementes, Brasília, DF, v. 18, n. 2, p. 149-155, 1996.

BORGES, E. E. L.; RENA, A. B. Germinação de sementes. In: AGUIAR, I. B.; PINA-RODRIGUES, F. C. M.; FIGLIOLIA, M. B. (Eds.). Sementes florestais tropicais. Brasília, DF: Abrates, 1993. p. 83-135.

BOVI, M. L. A. Cultivo da Palmeira Real Australiana visando à produção de palmito. Campinas: Instituto Agronômico, 1998. (Boletim técnico, 172).

BOVI, M. L. A.; CARDOSO, M. Conservação de sementes de palmiteiro (Euterpe edulis Mart.). Bragantia, Campinas, v. 37, n. 11, p. 65-71, 1978.

BRASIL. Ministério da Agricultura e Reforma Agrária. Regras para análise de sementes. Brasília, DF: SNDA/ DNDV/CLAV, 1992.

CARVALHO, N. M.; NAKAGAWA, J. Sementes: ciência, tecnologia e produção. 4. ed. Jaboticabal: Funep, 2000.

CHARLO, H. C. O. et al. Aspectos morfológicos, germinação e desenvolvimento inicial de plântulas de Archontophoenix alexandrae (F. Mueller) H. Wendl. e Drude (Arecaceae) em diferentes substratos. Revista Árvore, Viçosa, v. 30, n. 6, p. 933-940, 2006.

COSTA, P. A. et al. Quebra de dormência em sementes de Adenanthera pavonina L. Pesquisa Agropecuária Tropical, Goiânia, v. 40, n. 1, p. 83-88, 2010.

FERREIRA, S. A. N.; GENTIL, D. F. O. Extração, embebição e germinação de sementes de tucumã (Astrocaryum aculeatum). Acta Amazonica, Manaus, v. 36, n. 2, p. 141-146, 2006.

INSTITUTO BRASILEIRO DE GEOGRAFIA E ESTATÍSTICA(IBGE). Quantidade e valor dos produtos da extração vegetal e da silvicultura, segundo os principais produtos - Brasil. 2009. Disponível em: <http://www.ibge. gov.br/home/estatistica/economia/pevs/2009/default_pdf. shtm>. Acesso em: ago. 2011.

LEDO, A. S. et al. Efeito do tamanho da semente, do substrato e pré-tratamento na germinação de sementes de pupunha. Ciência Agronômica, Fortaleza, v. 33, n. 1, p. 29-32, 2002.

LORENZI, H. et al. Palmeiras brasileiras e exóticas cultivadas. Nova Odessa: Instituto Plantarum, 2004.

LUZ, B. P. et al. Germinação de sementes de PalmeiraReal-Australiana (Archontophoenix cunninghamii) sob efeito da imersão em água. Revista Agrarian, Dourados, v. 4, n. 11, p. 27-32, 2011.
MAGUIRE, J. D. Speed of germination-aid in selection and evaluation for seedling emergence and vigor. Crop Science, Madison, v. 2, n. 1, p. 176-177, 1962.

MARCOS FILHO, J. Germinação de sementes. Piracicaba: Fundação Cargill, 1986.

MARCUS, J.; BANKS, K. A practical guide to germination palm seeds. Palms, Lawrence, v. 43, n. 2, p. 56-59, 1999.

MARTINS, C. C.; BOVI, M. L. A.; NAKAGAWA, J. Desiccation effects on germination and vigor of King palm seeds. Horticultura Brasileira, Brasília, DF, v. 21, n. 1, p. 88-92, 2003.

MARTINS, C. C.; BOVI, M. L. A.; NAKAGAWA, J. Qualidade fisiológica de sementes de palmiteirovermelho em função da desidratação e do armazenamento. Horticultura Brasileira, Brasília, DF, v. 25, n. 1, p. 188192, 2007.

MARTINS, C. C. et al. Despolpamento e temperatura no armazenamento temporário de sementes de palmitovermelho (Euterpe espiritosantensis Fernandes). Revista Brasileira de Sementes, Brasília, DF, v. 22, n. 1, p. 169176, 2000a.

MARTINS, C. C. et al. Influência do peso das sementes de palmito-vermelho (Euterpe espiritosantensis Fernandes) na porcentagem e na velocidade de germinação. Revista Brasileira de Sementes, Brasília, DF, v. 22, n. 1, p. 47-53, 2000 b.

MARTINS, C. C. et al. Temporary storage of Jussara palm seeds: effects of time, temperature and pulp on germination and vigor. Horticultura Brasileira, Brasília, DF, v. 22, n. 2, p. 271-276, 2004.

MEEROW, A. W. Palm seed germination. Gainesville: University of Florida, 1991. (Bulletin, 274).

MIGLIANO, M. Todos no mesmo barco. Globo Rural, São Paulo, v. 17, n. 197, p. 39-44, 2002.

NASCIMENTO, W. M. O.; NOVEMBRE, A. D. L. C.; CÍCERO, S. M. Consequências fisiológicas da dessecação em sementes de açaí (Euterpe oleracea Mart.). Revista Brasileira de Sementes, Brasília, DF, v. 29, n. 2, p. 38-43, 2007.

SAEG: sistema para análises estatísticas: versão 9.1. Viçosa: UFV, 2007.

STRINGHETA, A. C. O. et al. Secagem e armazenamento de sementes de Palmeira Real Australiana (Archontophoenix alexandrae). Revista Brasileira de Armazenamento, Viçosa, v. 29, n. 1, p. 51-57, 2004.

VALLILO, M. I. et al. Composição química das sementes de Archontophoenix alexandrae H. Wendl. \& Drude (Arecaceae). Revista Árvore, Viçosa, v. 28, n. 5, p. 676679, 2004. 